\title{
CIDADE DEGENERADA? REFLEXÕES SOBRE SUA NATUREZA DEGRADADA E A (IM)PROPRIEDADE DA REGENERAÇÃO
}

\author{
DEGENERATED CITY? REFLECTIONS ON ITS DEGRADED NATURE \\ AND THE (IN)APPROPRIATENESS OF REGENERATION
}

\author{
VILLE DÉGÉNÉRÉE? RÉFLEXIONS SUR SA NATURE DÉGRADÉE \\ ET L'(IMPROPRIÉTÉ) DE LA REGÉNÉRATION
}

Rosemere Santos Maia - Universidade Federal do Rio de Janeiro - Rio de Janeiro - Brasil

rosemaia@terra.com.br
Carlos José Cândido Guerreiro Fortuna - Faculdade de Economia e Centro de
Estudos Sociais da Universidade de Coimbra - Coimbra - Portugal
cjfortuna@gmail.com

\begin{abstract}
Resumo
Neste artigo, pretendemos trazer à tona a discussão a respeito da natureza das metrópoles modernas, aqui entendidas como essencialmente degeneradas. Para tanto, recorremos a autores de diversas filiações teóricas - sobremaneira do âmbito da Filosofia, das Ciências Humanas e Sociais e da Teoria Social -, e a alguns exemplos que se tornaram "modelares" tanto para a discussão sobre 0 ambiente citadino, quanto para as intervenções urbanas que marcaram a virada do século $\mathrm{XIX/XX}$ e, mais recentemente, do século $X X$ até a contemporaneidade. Desta forma, colocamos em xeque a propriedade de prescrições e medidas regeneradoras, que, ao longo de mais de um século, têm feito das grandes cidades palcos e protagonistas de enredos nem sempre exitosos, em razão mesmo do "pecado original" que carregam.
\end{abstract}

Palavras-chave: Cidade, modernização, degeneração, regeneração urbana.

\begin{abstract}
In this article, we intend to bring out the discussion about the nature of modern metropolises, seen as essentially degenerated. As such, we turn to authors of different theoretical affiliations, particularly in the areas of Philosophy, Social and Human Sciences and Social Theory, and make use of some examples that have become "modular" both for the discussion of the city, and for urban interventions that marked the turn of the $19^{\text {th }} / 20^{\text {th }}$ century, and more recently, from the $20^{\text {th }}$ century on. Thus, we put into question the adequacy of prescriptions and regenerative measures that, over more than a century, have made the big cities to become stages not always very successful, due to the "original burden" cities have to carry.

Keywords: City, modernization, degeneration, urban regeneration.
\end{abstract}

Resumé

Dans cet article, nous voulons revenir sur la discussion concernant la nature des métropoles modernes considérées comme dégénérées. Pour cela, nous avons basé notre réflexion sur des auteurs appartenant à différents courants théoriques dans des domaines aussi variés que la philosophie, les sciences Humaines et sociales et la Théorie Sociale. Nous nous sommes également appuyés sur quelques approches "modulaires" aussi bien pour la discussion sur l'environnement de la ville que pour les interventions urbaines qui ont marqué le tournant du XIX/XXème siècles et, plus récemment, du XXème siècle jusqu'à nos jours. Nous avons ainsi mis en échec la propriété de prescriptions et de mesures régénératrices qui, au long de plus d'un siècle, ont 
fait des grandes villes des scènes et des acteurs de scénarios qui n'ont pas toujours été synonyme de succès en raison du « péché qu'elles représentent.

Mots-clés: Ville, modernisation, dégénération, régénération urbaine.

Introdução

Desde o surgimento do conceito de modernidade, em meados do século XIX, que a metrópole se tornou um dos "lugares" principais da reflexão. A partir de então, surgiram inúmeras teorizações elaboradas sobre as relações sociais estabelecidas no contexto urbano/metropolitano, em que o sentido do "moderno" foi repetidamente equacionado. A começar com a reflexão de Engels, mas, sobretudo, com os contributos de sociólogos como Simmel, Durkheim, Weber, Tönnies e Sombart - que se prolongariam em numerosas narrativas literárias e históricas - a modernidade da cidade confunde-se com a própria modernização da cultura e da sociedade em geral. Por detrás da ideia de modernidade, persiste com frequência a interrogação acerca do objeto que se renova. É sobre essa temática que se debruça este texto, num percurso que procura identificar alguns "momentos” em que se problematiza a ideia de modernização como regeneração do degenerado. A cidade degenerada parece a cidade no seu estado normal de existência, sujeita que fica, desde o seu primeiro momento, ao uso social e correspondente erosão. Nada dizemos dos “desastres" humanos ou naturais que, ao longo do último século e meio, tal como na antiguidade, afligiram as cidades e implicaram soluções estratégicas regeneradoras, muitas das quais constituíram verdadeiras ações de renovação e modernização da cidade. Também não abordamos diretamente a questão de saber até que ponto é o próprio "progresso" que muitas vezes ameaça as cidades ou as obriga a reformarem-se. Numa ou noutra situação, a solução regeneradora é parte de um fluxo contínuo que constitui a base da reflexão que aqui propomos, insistindo na ideia de que é a degeneração física e social da cidade e da metrópole que alimenta a sua permanente renovação.

Nesse sentido, partimos de uma pergunta central: a degeneração não será a verdadeira essência das cidades e metrópoles modernas?

\section{Sobre os "indícios"/"sintomas" de degeneração}

Olhando para a história - e, aqui, tomamos como marcos as transformações desencadeadas a partir da segunda metade do século XVIII - salta-nos aos olhos o nível de degradação prevalecente no ambiente 
urbano, nas cidades nascentes ou transformadas sob a égide do novo Capitalismo industrial. Engels (1975), em seu relato socioetnográfico e urbano "A situação da classe trabalhadora na Inglaterra”, situa a indústria no século XIX, como polo de atração da população, de mola propulsora de novos agrupamentos/cidades e de requisitante de infraestrutura, vias de comunicação, matérias-primas, máquinas e técnicas, assim como de mão de obra, necessárias à sua implementação. Ao mesmo tempo, o autor nos apresenta uma leitura política, por vezes chocante, do horror vivenciado pelas famílias operárias inglesas. Engels faz uma densa descrição da forma e do conteúdo dessa realidade, procurando demonstrar as dificuldades impostas aos sujeitos urbanos que, além da miséria material, tinham de pautar a sua condição na indiferença, no isolamento, no egoísmo e na precariedade dos seus direitos, num contexto, onde, segundo o mesmo autor, "até a própria multidão das ruas tem, por si só, qualquer coisa de repugnante, que revolta a natureza humana. (Engels, 1975, p. 56).

Isso nos coloca diante do que, à primeira vista, seria um paradoxo original que parece acompanhar as cidades desde a sua fundação: sua natureza e origem deteriorada e degenerada contrapõem-se à racionalidade, à técnica e tudo o mais correspondente à lógica filosófica da mercadoria. A cidade já surge, assim, como um ambiente degradado, marcado pela insalubridade, pelas doenças, pela poluição ambiental, por uma prática social empobrecida, tal qual também descrito por Mumford (1991, p. 484) ao referir-se aos "montes de homens, parques de máquinas, e não meios de associação humana, tendo em vista a promoção de uma vida melhor". Segundo o autor, "o industrialismo, a principal força criadora do século XIX, produziu o mais degradado ambiente urbano que o mundo jamais viu; na verdade, até mesmo os bairros das classes dominantes eram imundos e congestionados" (1991, p. 484). Com isso, Mumford chama a atenção para os efeitos "nocivos" decorrentes do progresso da indústria nascente. Estes seriam um custo visível na degradação ambiental geral e da paisagem, conduzindo a uma desordem do ambiente comunal (p. 488).

Tanto o modo de vida, quanto a subjetividade do homem metropolitano foram afetados pela forma e pelas relações sociais desenvolvidas na cidade, a exemplo do que, mais tarde, já no início do século XX, seria sustentado por Simmel (2005) - (ao referir-se contatos efêmeros e superficiais, à intelectualização do "self”, e à atitude blasé) (Fortuna, 2014) - e Wirth (1987) - ao mencionar o enfraquecimento dos laços sociais e as 
relações utilitaristas travadas entre os sujeitos sociais no meio urbano. Há de se ressaltar, contudo, que se, por um lado, tais características tendem a sugerir prejuízos substantivos em termos de relações sociais, por outro lado, podem deixar claro que a complexificação dos agrupamentos humanos e a emergência das grandes cidades, também acabaram por viabilizar uma maior tolerância frente à diversidade, a heterogeneidade, a uma maior autonomia dos indivíduos e grupos sociais, tanto quanto uma menor rigidez em relação ao status social, além de outras formas de controle social e novas estratégias de defesa da personalidade individual.

Walter Benjamin trataria tal quadro de diversidade sob o ângulo da "porosidade" da cidade. Para o reconhecido pensador, a cidade de Nápoles seria o exemplo de tal condição "porosa" em que o velho se mistura com o novo e as lógicas de conservação do urbano se combinam e articulam com a degeneração e decadência e transitoriedade do edificado. Assim a cidade renova-se a cada instante dada a importância daquilo que parece estar escondido no seu regular fluir histórico (Benjamin, 1978).

\section{A busca da regeneração}

Frente a esse quadro tão complexo de novas sociabilidades urbanas, onde inúmeros sintomas de degradação se apresentavam no exato momento em que as cidades industriais surgiram e se desenvolveram, é compreensível que as mazelas apresentadas (tanto aquelas referidas propriamente à forma urbana, quanto às derivadas do seu conteúdo - ou seja, das relações estabelecidas entre os citadinos) logo tenham suscitado iniciativas com o intuito de "tratá-las". Era, de alguma forma, a busca da "regeneração", o que, de certo modo, parece indicar um paradoxo, haja vista que não houve um aviltamento à ordem, um desgaste ou deterioração das cidades, à medida que a suposta "ordem urbana" nunca existira. $\mathrm{O}$ sentido aqui depreendido é o de que regenerar significava no mínimo, aprisionar a decadência, ou seja, evitar que possa se deteriorar mais do que já está. Mas pode também significar a promoção de melhorias na cidade, sem pretender reconstruir um ambiente que fora destruído ou arruinado - já que isso pressuporia que ela tivesse nascido "sã” e perfeita como se o início da cidade pudesse traduzir também o tempo/lugar em que começa a sua continuada degradação. 
As condições precárias das cidades modernas, que invariavelmente surgem indicadas como nascidas, sobretudo a partir de meados do século XIX, igualmente inspiraram análises realizadas pelas Ciências Sociais (também nascentes), pela Economia Política, bem como por outros campos disciplinares que se desenvolveram com a razão técnica e a especialização - como a Arquitetura e Urbanismo, a Medicina Social. Motivaram práticas higienistas, mas também mobilizaram sindicatos, filantropos, assistentes sociais, "gestores" públicos e políticos (Rodwin; Hollister, 1984). Segundo Françoise Choay (2006), as reflexões acerca da natureza das cidades emergidas nesse contexto, e que, de algum modo, serviram de inspiração para intervenções mais "práticas” (em termos de planejamento, de políticas urbanas e sociais) partiram, basicamente, de dois grupos bem demarcados: de um lado, os que apresentavam uma postura humanista - em geral médicos e higienistas sensibilizados com os problemas derivados das novas relações de trabalho, da insalubridade e de toda sorte de deficiências existentes nas cidades; de outra parte, situavam-se os polemistas - pensadores políticos que dirigiam severas críticas à sociedade industrial que se impunha e das repercussões que provocava no meio citadino.

Foi também nesse contexto de "degradação" socioambiental que surgiram as "classes perigosas", categoria usada correntemente pela burguesia, desde o começo da Revolução Industrial, para referir-se aos habitantes dos bairros operários das grandes cidades (Topalov, 1996). Na visão de Topalov, tal categoria tanto servia para descrever uma massa humana indiferenciada, habitante de espaços urbanos bem delimitados propensos a enormes flagelos sociais e sanitários, como, com o passar dos anos, passou a ser referida àqueles que não se enquadravam ao projeto de modernidade da burguesia: desempregados, vagabundos, retardados, delinquentes juvenis.

Algumas propostas visando o enfrentamento da "degeneração" das cidades, ou de sua inadequação e a dos sujeitos que nela habitavam à nova ordem burguesa exigida pela fase do capitalismo, em fins do século XIX, são bem conhecidas. A mais "inspiradora" talvez tenha sido a Reforma de Paris, levada a termo pelo Barão Haussmann, ocupante do cargo de prefeito da Cidade, entre 1853-1870, que atendendo a determinações de Napoleão III, interveio cirurgicamente sobre a capital francesa, tornando-a "modelar" para a época. 
Desafiado a transformar Paris numa cidade moderna, Haussmann se viu diante de grandes dificuldades decorrentes da herança urbana medieval da cidade, muito particularmente o caso das ruas estreitas e sinuosas de Paris, que impunham graves obstáculos a cada vez mais célere circulação, nomeadamente à ação das forças militares em caso de insurreição popular e de levantamento de barricadas. Esta feição militarista da reforma urbana da Paris de Haussmann surge retratada por Walter Benjamin, ao afirmar que o referido Prefeito buscou "encontrar apoio para a sua ditadura e colocar Paris sob um regime de exceção [tornando] a cidade segura em caso de guerra civil. Ele queria tornar impossível que no futuro se levantassem barricadas em Paris. [...] Os contemporâneos batizam esse empreendimento de 'embelissement stratégique' [embelezamento estratégico]” (Benjamin, 1985, p. 41-42, grifo nosso).

Regenerar a cidade seria, então, não só modernizá-la, mas também higienizá-la, e torná-la livre de tudo o que pudesse macular sua imagem, com destaque para a degradante pobreza, ou o potencial insurrecional das classes perigosas. Essa seria a via da transformação de Paris, como de qualquer outra metrópole apostada na modernidade: uma cidade movida pela razão burguesa e os imperativos do mercado, da produção e do consumo.

As transformações haussmanianas de Paris serviram de modelo para outras tantas cidades não só europeias, mas de outras "latitudes", designadamente na América Latina. Com efeito, já no início do século seguinte, um exemplo desta "exportação" de Haussmann encontra-se nas reformas empreendidas por Pereira Passos no Rio de Janeiro, entre 19021906. Tais reformas revelam uma profunda inspiração francesa ficando evidenciada a força do discurso higienizador que marcava as intervenções urbanas naquele momento.

A modernidade que se almejava, então, não dizia respeito a um desejo qualquer de ilimitada valorização da novidade. Modernidade significava, sobretudo, a possibilidade do porvir, do futuro, da transformação. A cidade era o lócus privilegiado de uma vislumbrada mudança e da adoção de todos os fenômenos, traços e processos prometido pela revolução industrial: máquinas, arquitetura, meios de transportes, velocidade, novos padrões e novos lugares de consumo, além de novos atores sociais que, submetidos ao anonimato, transformavam-se em multidão.

Ao mesmo tempo em que colocava a possibilidade da abertura e da unificação, a cidade moderna revelava as suas fraturas, segregava, 
discriminava e deixava cada vez mais claro que, nas palavras de Paul Singer, "a cidade capitalista não tem lugar para os pobres. A propriedade privada do solo urbano fez com que a posse de uma renda monetária se tornasse requisito indispensável à ocupação do espaço urbano" (Singer, 1982, p. 33). Isto fica ainda mais claro quando Berman, no seu notável livro sobre a ordem urbana moderna (Berman, 1996), ao referir-se aos "efeitos" provocados pela criação dos bulevares, retrata o incômodo provocado pela presença dos pobres (a "família de olhos" descrita por Baudelaire, no Spleen de Paris) aos segmentos mais abastados das novas paisagens urbanas.

Embora, como já mencionado, a "reforma" empreendida por Haussmann tenha se tornado paradigmática naquele contexto, não podemos deixar de nos referir a outras iniciativas levadas a termo, ou a outros modelos, que embora surgidos noutras geografias da modenização europeia de industrialização crescente, denunciam a marca haussmanniana da intervenção. É o caso do plano de Ildefons Cerdá, para Barcelona (1855), ou ainda o idealizado por Otto Wagner, para Viena (1890). Todos, no fundo, partindo da constatação da necessidade de se adequar (ou seria melhor dizer, regenerar?) a cidade, tendo em vista as necessidades e determinações impostas pelos tempos modernos.

Na Europa anterior à Guerra de 1914-18, este surto modernizador ajudou a estabelecer um padrão urbano do que seria a cidade moderna. Subitamente, o eclodir do conflito viria a pôr termo a esta visão europeísta da modernidade, ilustrada pelas suas metrópoles mais dinâmicas (Londres, Paris, Viena, Berlim e mesmo Moscovo). A interrupção modernizante e depois modernista da Europa, como que indiretamente, fez surgir Nova Iorque enquanto modelo dominante de cidade adequada aos "novos tempos". De um lado, a multiplicação dos arranha-céus (por exemplo, o Rockefeller Center) e, de outro lado, o surgimento de parques de diversão (Dreamland em Coney Island) traziam consigo uma nova configuração e um renovado espírito de divertimento e lazer à modernidade urbana (Arantes, 2011). Só com a arquitetura típica do movimento modernista do pós-guerra, a cidade europeia regressaria ao seu interrompido desígnio de modernização.

\section{Entre análises e prescrições}

Sem prejuízo desse acidentado percurso histórico, ao longo do século XX, à medida que as relações capitalistas se transformavam e 
dava-se a expansão urbana, novas necessidades surgiram, novos padrões de organização e gestão da produção e do consumo se colocaram, levando a uma alteração na própria natureza das cidades, bem como do próprio sentido da regeneração urbana (ou, quem sabe, de uma melhor compreensão do seu sentido). Um extenso "receituário" foi prescrito por arquitetos e urbanistas, grupos sociais se mobilizaram na luta por uma "cidade para todos", a academia se voltou para a Cidade enquanto "objeto de investigação", administradores locais estabeleceram planos e projetos de intervenção. A cidade tornara-se, definitivamente, "protagonista”, objeto de investigação e intervenção, deixando de ser exclusivamente palco das relações sociais engendradas pela ordem capitalista.

Ebenezer Howard (1850-1928), Le Corbusier (1887-1965), Kevin Lynch (1918-1984), François Ascher (1946-2009), dentre tantos outros, empreenderam esforços em pensar e prescrever alternativas para as cidades, em geral partindo da observação da sua natureza degenerada. Tratados, normativas, acordos também foram, ao longo dos anos, estabelecidos com o mesmo propósito, a cada tempo tendo algum aspecto na ordem do dia - como a salubridade, a mobilidade, a justiça social e o direito à cidade, a sustentabilidade urbana. Pesquisadores voltaram-se para a cidade e seus "problemas", posto que à medida que a questão social se apresentava, manifesta-se, igualmente, a questão urbana (Castells, 1983). Assim ocorreu nos estudos empreendidos pela Escola de Chicago (desde a primeira geração de pesquisadores - Robert Ezra Park, considerado o grande ícone e precursor dos estudos urbanos, Ernest Watson Burgess e Roderick Duncan McKenzie; passando posteriormente por Frederic Thrasher, Louis Wirth e Everett Hughes), pela Sociologia Urbana Francesa, a partir dos anos 1960 (com Chombart de Lauwe e seus colaboradores, Henri Lefebvre, Raymond Ledrut e, posteriormente, nas reflexões empreendidas por Castells e Topalov), além daqueles desenvolvidos por inúmeros laboratórios de investigação presentes em várias partes do mundo.

Organizações supranacionais (como a ONU), Estados Nacionais, governos locais, lideranças políticas, grupos organizados da sociedade civil e representantes de categorias profissionais (como a dos arquitetos, por exemplo - através da Carta de Atenas de 1933 e a sua nova versão, de 1998) passaram, num crescendo, a pensar em propostas e estabelecer acordos, pactos, convenções em função do reconhecimento do rápido e crescente processo de urbanização como um fenômeno presente em 
escala mundial. Fenômeno esse que não só provoca enormes impactos ambientais, deixando marcas indeléveis no Planeta, como igualmente acarreta o aprofundamento das mazelas urbanas,

como a falta de oferta de emprego, a expansão de assentamentos irregulares, o aumento da pobreza e da desigualdade socioeconômica, a inadequação das infraestruturas, a falta de equipamentos públicos, o uso impróprio do solo urbano, a insegurança quanto à posse da terra, o crescimento desordenado das cidades e o aumento das vulnerabilidades [...] (Brasil em desenvolvimento 2015, p.268)

Importantes fóruns de discussão - mesmo onde a cidade não se apresentava como centro da discussão, passaram a trazer o contexto urbano como tema, apontando toda sorte de problemas nele existentes. Assim ocorria tanto a nível local, nos debates que envolviam atores sociais em diferentes cidades do mundo - onde temas como poluição, violência, falta de habitação, desprezo em relação ao patrimônio, desemprego, pobreza, desigualdade etc., eram pautados com frequência, como em espaços de debate propostos por organizações interestatais ou supranacionais, a exemplo das conferências promovidas pela ONU (tais quais as que discutiam o meio ambiente e a Cidade - Estocolmo 1972, Eco 92, Habitat II, Rio +20 , e o Fórum Urbano Mundial), por instituições econômicas, como Fórum Econômico Mundial, ou ainda promovidos por movimentos sociais com perspectiva altermundialista (movimento da justiça global), como tem sido o caso do Fórum Social Mundial, dentre outros. Embora as propostas emanadas dos fóruns/debates acima mencionados nem sempre fossem convergentes e/ou enfrentassem a origem ou essência desses problemas, era patente o reconhecimento da necessidade de intervenções sobre o ambiente urbano.

\section{A (im)propriedade da regeneração}

Se a história tem se mostrado prenhe de modelos, propostas, críticas, questionamentos, teorias sobre e para as cidades, afirmando seu caráter inadequado, impróprio e problemático já na sua essência, na sua constituição, voltamos, então, para a questão que colocamos logo no início desse artigo: a cidade teria, em si, uma natureza degenerada? E quanto ao "conceito" ou às intervenções de regeneração urbana: partindo do fato de que as cidades nunca foram marcadas por uma situação ótima, 
de adequação, de salubridade, de organização, propor regenerá-las seria apropriado? Ou, em outras palavras, a regeneração só teria lugar caso pudéssemos constatar que, ao longo do tempo, ocorreu um afastamento em relação a essas suas qualidades projetadas, o que forçosamente indicaria processos crescentes de degradação, deterioração? Esse é, em geral, o sentido de degeneração encontrado nos dicionários, demonstrando sempre uma situação de declínio, estrago, quebra de virtudes, adulteração, definhamento.

Não se pretende, aqui, negar que, em alguns contextos/situações e momentos históricos, as cidades de fato passaram/passem por processos de aprofundamento de algumas problemáticas (sejam elas de ordem infraestrutural, social, patrimonial, econômica, política, ambiental), apontando para a perda de alguma qualidade que, algum dia, tenham apresentado e, em função disso, demandando intervenções, enfrentamento. Entretanto, o fato de questões X ou Y terem apresentado um crescimento exponencial, terem se tornado crônico ou se agudizado num determinado tempo e espaço, não significa que, anteriormente, já lá não estivessem presentes. Desta forma, falar em regeneração não faria sentido caso esse tipo de intervenção significasse um esforço de restabelecer ou restaurar uma situação "ótima”, de salubridade já experimentada num momento pretérito; em contrapartida, poderia significar favorecer uma nova existência, melhorar, corrigir imperfeições, ou mesmo formar algo novo (Frisby, 2001).

Olhando para a contemporaneidade e para tudo o que se tem falado, teorizado e prescrito em relação ao ambiente urbano, podemos então supor que a cidade degenerada é aquela que se distancia de alguns requisitos básicos, de um "modelo de cidade”, ou um tipo-ideal, num contexto onde as cidades passaram a se constituir em locais privilegiados de articulação de interesses econômicos e tecnológicos, orientadas por uma visão estratégica em relação ao planejamento urbano.

Regenerar a cidade, nesse sentido, seria inseri-la no que se convencionou chamar de mercado mundial de cidades, através do investimento em atividades vinculadas ao terciário avançado, assim como a descoberta e/ou reforço de elementos que expressem a vocação de cada uma delas, a sua marca, seu "diferencial" em relação às demais. (Maia, 2006, p. 63)

O que agora prevalece é uma interpretação da cidade moderna como cidade global (Sassen, 1991) entendida como nova geografia que, há um 
tempo, qualifica e desqualifica espaços e territorialidades urbanas, em função da sua adequação aos desígnios da competição internacional. Para a geógrafa crítica Doreen Massey, no novo contexto, as recentes diferenças espaciais existentes entre países, comunidades e cidades expressam-se em termos temporais de tal modo que a "homogeneização" das cidades ou sua subsunção aos imperativos da globalização passam a ser vistas apenas como uma questão de tempo. (Massey, 2005)

Roberts e Sykes (2000, p. 17), na tentativa de melhor esclarecerem conceitualmente o que vem sendo chamado de regeneração urbana, atribuem-lhe uma visão abrangente e integrada de ação que leva à resolução dos problemas urbanos e que procura proporcionar melhorias duradouras no domínio econômico, na condição física, social e ambiental de uma área que tem sido submetida à alteração.

Mendes (2013), tentando contribuir para a discussão, sustenta que a regeneração urbana é

uma nova política urbana que procura a requalificação da cidade existente, desenvolvendo estratégias de intervenção múltiplas, orquestrando um conjunto de ações coerentes e de forma programada, destinadas a potenciar os valores socioeconômicos, ambientais e funcionais de determinadas áreas urbanas, com a finalidade de elevar substancialmente a qualidade de vida das populações residentes. (Cochrane, 2007; Tallon, 2010 apud Mendes, 2013, p. 36)

No entanto, cremos não se tratar, tão somente, de uma estratégia política que visa elevar substancialmente a qualidade de vida das populações residentes. Antes disso, o que se tem em vista é a qualificação da cidade enquanto mercadoria a partir dos insumos que detêm e que são valorizados pelo capital transnacional, a exemplo do sugerido por Borja e Forn (apud Vainer, 2002, p. 79). Tais insumos seriam, segundo os mesmos autores, todo um conjunto de infraestruturas e serviços capazes de atrair "investidores, visitantes e usuários solventes à cidade e que facilitem suas 'exportações' (de bens e serviços, de seus profissionais, etc.)." (Borja; Forn apud Vainer, 2002, p. 80). Em alguma medida, o discurso que sustenta essas propostas é, segundo explicitado também por Mendes (2013, p. 36), o de que "qualquer iniciativa será tanto mais bem-sucedida quanto melhor responda a interesses e expectativas dos atores e agentes envolvidos nos processos, enquadrando-os e envolvendo-os na tomada de decisões." 
Os "novos" sintomas de degeneração

Como "sintomas" da degeneração - e aqui tomamos como referência os discursos e as práticas dominantes nos dias hodiernos, poderíamos elencar alguns elementos/fenômenos que, vistos isoladamente, ou associados, são passíveis de comprometer o modelo de cidade perseguido contemporaneamente:

- Aspectos econômicos e infraestruturais: economia voltada para o mercado local, de autossubsistência, pautada em atividades/ relações tradicionais, que exigem pouca qualificação daqueles que as desenvolvem, incapazes de atrair investimentos e consumidores qualificados e de ultrapassar as fronteiras da cidade onde se apresentam. Ausência de investimentos em tecnologias de informação, transporte e mobilidade, segurança, serviços financeiros, publicidade/marketing, centros de formação (a nível técnico/tecnológico e científico/de investigação), espaços de cultura e lazer, hotéis e centros de convenções etc. Ausência de equipamentos, serviços e infraestrutura capazes de atender e/ou atrair investimentos necessários à demarcação e consolidação de um lugar estratégico (ou de destaque) a ser ocupado pela cidade na nova economia urbana, levando-a a uma situação de incapacidade de se apresentar em condições de competitividade ou, ainda, provocando uma situação de ostracismo.

- Aspectos políticos: Prevalência de formas arcaicas de administração urbana, onde não se aposta na sua gestão aos moldes de uma empresa, um dos requisitos básicos demandados às cidades pelo capitalismo contemporâneo. Não se atribui importância à figura do administrador (gestor de cidades) como um sujeito cuja liderança política é enaltecida por sua "competência técnica capaz de situá-lo acima da política” (Sanchez, 2001, p. 40); a figura do político prevalece sobre a do "Prefeito empreendedor", este sim detentor da missão de "desencadear planos e projetos estratégicos associados à reestruturação urbana” (é como, por exemplo, se os interesses do partido tivessem ascendência sobre os interesses da cidade). Na gestão da cidade, não se valoriza o papel a ser desempenhado pela iniciativa privada, através das parcerias estabelecidas com o Poder Público, na promoção de investimentos capazes de atrair recursos e consumidores 
qualificados. A população não se vê representada ou não adere ao projeto pensado para a cidade, manifestando sua contrariedade através de manifestações, insurreições, atos considerados como "vandalismo". Recursos midiáticos não são utilizados como peças-chaves eficientes e ostensivas para a "potenciação dos processos de informação [...] pelos governos das cidades" na relação entre a administração pública e os cidadãos, favorecendo a produção simbólica. (Sanchez, 2001, p. 37)

- Aspectos socioespaciais: crescimento da violência e do medo, bem como da percepção, por parte dos citadinos, de processos que (re)produzem desigualdades no acesso à infraestrutura e serviços coletivos, contribuindo para a fragmentação do tecido sociopolítico e espacial (Souza, 2000) e para a exacerbação de estigmas, preconceitos, frutos de intervenções e ações que aprofundam a guetificação e a segregação, sem falar nos constrangimentos à mobilidade urbana. A estigmatização territorial também pode produzir

entre os moradores estratégias sociófobas de evasão e distanciamento mútuos e exacerba processos de diferenciação interna, que conspiram em diminuir a confiança interpessoal e em minar o senso de coletividade necessário ao engajamento na construção da comunidade e da ação coletiva.(Wacquant, 2005, p. 33).

Emergência de insurreições, de manifestações públicas/coletivas, de práticas sociais que indicam insatisfação em relação aos rumos tomados pela cidade, ou mesmo inadequação das intervenções realizadas por gestores locais, colocando em risco a "ordem urbana” e a legitimidade dos administradores da cidade. Tais práticas podem revelar as assimetrias que se materializam no espaço urbano, derivadas tanto das contradições decorrentes da estrutura econômica, quanto daquelas engendradas no âmbito da esfera política e/ou cultural/simbólica.

- Aspectos culturais/históricos/patrimoniais: cultura e patrimônio apresentam-se como elementos "cristalizados", impermeáveis às imposições da nova economia urbana e aos influxos da globalização. Constata-se, desse modo, uma resistência a pensá-los como mercadorias, em plena sintonia com imperativos da nova ordem econômica e política que rege 
a cidade. Os elementos constitutivos da tradição, passíveis de serem "exercitados comumente, sem recurso a quaisquer protocolos mentais ou práticos", sobrepõem-se às iniciativas de patrimonialização, cujos

objetos, lugares ou práticas socioculturais patrimonializados passam, ipso facto, a ser entendidos como fim em si mesmos [sendo passíveis de ] surgir desligados da realidade imediata e do presente vivido, assim como também desvinculados dos usos sociais concretos que terão servido. (Fortuna, 2012, p. 25).

Elementos culturais tornam-se aprisionados a um passado, sem que seja enfatizada "a noção de continuidade, coesão e pertença"; onde eles operariam como "fontes de mediação de uma memória referente a um local e a um tempo que, perante a impossibilidade de serem recuperados são, assim, recriados no presente" (Anico, 2005, p. 77-78) e, na medida do possível, otimizados de forma a produzir lucro, a atrair consumidores qualificados para a cidade. Não se potencializa a cultura e o patrimônio como estratégias para estabelecimento de uma marca para a cidade, o que é fundamental num momento em que ela (a marca) também é utilizada para promover a diferenciação entre as cidades (Alfonso, 2003), torná-las competitivas. Cultura e patrimônio aparecem dissociados da indústria do turismo, cada vez mais importante para a nova economia urbana.

- Aspectos simbólicos: Dificuldade de difusão e de entronização junto aos citadinos de uma "imagem síntese oficial" que seja capaz de garantir sua adesão ao projeto de modernização urbana que se persegue. Essas imagens, segundo Sanchez (2001, p. 34),

não deixam margem para dúvidas ou interpretações diversas sobre a informação que veiculam; não oferecem alternativas à sua decodificação. Organizam, a seu modo, a cidade, tornando-a simbolicamente eficiente, uma espécie de publicidade que concretiza o modo de reconhecê-la e avaliá-la.

Assim, são capazes de despertar um tipo de "participação [contemplativa] dos cidadãos, o sentido de pertencimento à cidade, a adesão aos novos projetos ou serviços oferecidos, o elevado grau de aceitação e aprovação pública dos "projetos de cidade". 
(Sanchez, 2001, p. 41). Constata-se uma deficiência dos meios midiáticos ou uma apropriação inadequada da mídia por parte dos gestores, o que vai de encontro ao papel que dela é esperado para fazer valer o "modelo de cidade" vislumbrado, contrariando aquilo que é mencionado por Canclini a respeito do papel por ela esperado pelos detentores do poder - ou seja, reprodução da ordem social, "uma função de mimese, de cumplicidade com as estruturas sócio-econômicas e com os lugares comuns da cultura política [editando] as vozes dissidentes ou excluídas de maneira a preservar o status quo.” (Canclini, 2002, p. 50)

- Aspectos ambientais: ausência de preocupação com a sustentabilidade urbana, não sendo verificadas ações, tampouco pactos políticos capazes de evitar a degradação do ambiente (esse entendido não somente como físico, mas também social), tendo em vista o enfrentamento de desafios presentes e futuros colocados às cidades no que se refere à gestão ambiental. Presença de fatores que promovam desequilíbrios nas condições ambientais, impactando não somente na localidade, mas demonstrando níveis de externalidades negativas sobre outras regiões (tanto próximas, como distantes) no presente, mas podendo levar a desdobramentos futuros. (Urban world forum, 2002; Acserald, 1999). Situações que demonstrem condições inadequadas de uso da água, do solo, verificação de agentes provocadores de poluição (sob todos os aspectos), sistema inadequado de tratamento de resíduos, dentre outros fatores.

\section{Considerações finais}

Mesmo diante de tantas prescrições/recomendações, a forma como o capitalismo se organiza na contemporaneidade, e que levou mesmo a que tenha sido tratado como desorganizado (OFFE, 1985), acaba por comprometer a aproximação ao modelo de cidade desejado, o que deixa claro que, enquanto "modelo", ele se trata de um "tipo ideal". Crises econômicas, de gestão política, aprofundamento das desigualdades sociais e intraurbanas, quebra/falta de valores éticos, individualismo, degradação ambiental - esses podem ser fatores a demonstrar que uma cidade jamais conseguirá abster-se de algum indício de degeneração, por menor que seja. 
Há ainda uma questão importante a ser mencionada: a degeneração, vista sob a ótica dominante, pode constituir-se enquanto um problema, mas, para além das intervenções e ações que teimem em combater seus "sintomas", há de se considerar a riqueza nela contida - justamente pelo fato de trazer à tona os paradoxos e contradições que marcam as relações econômicas, sociais e políticas contemporâneas, a forma como cada cidade lida com questões como patrimônio e cultura, além dos danos que vêm sendo provocados à natureza. Tal riqueza também se apresenta na ambiguidade e porosidade que ela contém: o que para os detentores do poder pode ser visto como degeneração, para os segmentos subalternos pode ser encarado como possibilidade de tomada de consciência dessas contradições, de emergência de ações de resistência e empoderamento, de participação, de identidade positiva, de ressignificação simbólica, de práticas sociais e culturais criativas e de contra-usos do espaço público - contribuindo para a afirmação do vernacular, por meio da redução das assimetrias presentes na paisagem urbana. (Zukin, 2000, p. 84) .

As iniciativas de regeneração urbana que têm sido levadas a cabo desde os anos 1990, muitas delas - as mais recentes - inspiradas naquelas empreendidas na cidade de Barcelona - tornada modelo de planejamento urbano estratégico, são campos férteis de análises e indicam um sem número de paradoxos e/ou impropriedades que nos levam, mais uma vez, a questionar a validade das propostas e das práticas sustentadas numa suposta "regeneração" urbana. Multiplicam-se e repetem-se continuamente em várias cidades do mundo - que assim vão ficando exauridas - intervenções e prescrições alinhadas aos chamados processos "RE", que legitimadas por discursos que sustentam a necessidade de adequação das cidades às demandas do terciário avançado - via transformação de áreas degradadas e espaços obsoletos em locais de investimento, enobrecidos, dinâmicos, com "vitalidade" (como se antes fossem desprovidas de vida), não raras vezes promovem/aprofundam as desigualdades intraurbanas, bem como os processos de segregação socioespacial. Aqui, muitos exemplos poderiam ser mencionados, mas não poderíamos deixar de fazer alusão àqueles que, em plena sintonia com o "Modelo Barcelona" - mas insensíveis à sua crítica (Delgado, 2007), sobretudo por estarem alinhados a um "projeto olímpico", nos levam a questionar a tão propalada "regeneração".

Através do recurso a elementos imbuídos de forte apelo simbólico - como o esporte, a positividade do legado a ser deixado para a cidade, o sentimento generalizado de crise do modelo urbano até então vigente, o 
lugar de destaque a ser alcançado pela cidade que se abrir às iniciativas de regeneração - algumas cidades são "reedificadas", tendo como parâmetros os interesses de grupos e instituições dominantes (empresários, organizações supranacionais e esportivas, etc.), consolidando mais e mais a assimetria de poder sobre a qual falara Zukin, "opondo as intervenções dos poderosos à chancela dos sem poder” (Zukin, 2000, p. 84). Dissidências, quando surgem, são imediatamente anuladas, criminalizadas, e as vozes que se manifestam ou denunciam os desmandos e usurpações de direitos são prontamente caladas, neutralizadas.

Foi assim em Atenas, em Barcelona, na Cidade do Cabo, em Johanesburgo e não tem sido diferente no Brasil, sobretudo nas cidades eleitas como sedes da FIFA World Cup (2014), e principalmente tem sido a regra no Rio de Janeiro, alçado ao patamar de Cidade Olímpica. A exemplo do aluno que supera o mestre, o Rio parece ter alcançado um estatuto capaz de deixar Barcelona (a "musa inspiradora") recolhida à sua "insignificância”, caso tomemos como parâmetro a magnitude do legado (para o "bem" ou para o "mal”) a ser deixado à Cidade por força das parcerias estabelecidas entre o Poder Público e a iniciativa privada.

Nesse preciso momento, tal como ocorre no Rio, outras "novas Cidades" são gestadas em várias partes do mundo, apresentando as deformidades e vícios ainda durante o período gestacional, o que nos remete ao que sustentamos desde o início: em se tratando do ambiente urbano, a degeneração é um atributo essencial, uma força motriz, capaz de revelar as imperfeições e, mais que isso, de por em xeque a propriedade e eficácia de quaisquer medidas/iniciativas regeneradoras que proponham a cura do pecado original que as Cidades naturalmente carregam.

\section{Agradecimentos:}

Rosemere Maia agradece apoio concedido pela CAPES para realização de seu estágio pós-doutoral da Universidade de Coimbra, sob supervisão do Prof. Carlos Fortuna.

\section{Referências}

ACSERALD H. Discursos da sustentabilidade urbana. Revista Brasileira de Estudos Urbanos e Regionais, Campinas, n. 1, maio 1999. 
ALFONSO, M. J. P. El patrimonio cultural como opción turística. Horizontes Antropológicos, Porto Alegre, v. 9, n. 20, out. 2003. Disponível em: <http://dx.doi. org/10.1590/S0104-71832003000200006>. Acesso em: 05 fev. 2016.

ANICO, M. A pós-modernização da cultura: património e museus na contemporaneidade. Horizontes Antropológicos, Porto Alegre, v. 11, n. 23, jan./jun. 2005. Disponível em: <http://dx.doi.org/10.1590/S0104-71832005000100005>. Acesso em: 28 dez. 2015.

ARANTES, O. Chai-na. São Paulo, EDUSP, 2012.

BAUDELAIRE, C. Pequenos poemas em prosa (Le Spleen De Paris). s.d. Disponível em: <https://iedamagri.files.wordpress.com/2014/07/baudelairespleen-de-paris.pdf>. Acesso em: 08 dez. 2015.

BENJAMIN, W. Paris, capital do século XIX. In: KOTHE, F. R. (Org.). Walter Benjamin. São Paulo: Ática, 1985.

. Reflections: essays, aphorisms, autobiographical Writings. Ed. and intro. Peter Demetz. Trans. Edmund Jephcott. New York: Harcourt Brace Jovanovich, 1978.

BERMAN, M. Tudo que é sólido desmancha no ar: a aventura da modernidade. São Paulo: Companhia das Letras, 1996.

BRASIL EM DESENVOLVIMENTO 2015: Estado, planejamento e políticas públicas / Editores: André de Mello e Souza, Pedro Miranda. Brasília, Ipea, 2015. 292 p. Disponível em: <http://www.ipea.gov.br/portal/images/stories/PDFs/ livros/livros/bd_2015_web.pdf>. Acesso em: $10 \mathrm{dez} .2015$.

CANCLINI, N. G. Cidades e cidadãos imaginados pelos meios de comunicação. Opinião Pública, Campinas, v. III, n. 1, p. 40-53, 2002.

CASTELlS, M. A questão urbana. Rio de Janeiro: Paz e Terra, 1983.

CHOAY, F. A alegoria do patrimônio. São Paulo: Editora da Unesp/Estação Liberdade, 2006.

DELGADO, M. La ciudad mentirosa. Frause y miseria del "Modelo Barcelona”. Madrid: Catarata. 2007.

ENGELS, F. A situação da classe trabalhadora na Inglaterra. Porto: Edições Afrontamento, 1975.

FORTUNA, C. Georg Simmel: a metrópole e a alegoria da ruína. In: PECHMAN, R. M. (Org.). A pretexto de Simmel: cultura e subjetividade na metrópole contemporânea. Rio de Janeiro: Letra Capital, 2014.

- Património, turismo e emoção. Revista Crítica de Ciências Sociais [Online], 97, 2012. Disponível em: <http://rccs.revues.org/4898>. Acesso em: 03 jan. 2016.

FRISBY, David. Cityscapes of modernity. Cambridge: Polity, 2001.

MAIA, R. Políticas urbanas no Rio de Janeiro: requalificação, reordenamento e controle social na busca de competitividade no "mercado mundial" de cidades. In: GOMES, M. de F. C. M. (Org.). Cidade, transformações no mundo e políticas públicas. Rio de Janeiro: DP\&A, 2006. p. 62-78. 
MASSEY, D. Pelo espaço: uma nova política da espacialidade. Rio de Janeiro: Bertrand Brasil, 2005.

MENDES, L. A regeneração urbana na política de cidades: inflexão entre o fordismo e o pós-fordismo. Urbe. Revista Brasileira de Gestão Urbana (Brazilian Journal of Urban Management), v. 5, n. 1, p. 33-45, jan./jun. 2013.

MUMFORD, L. A cidade na História: suas origens, transformações e perspectivas. São Paulo: Martins Fontes, 1991.

OFFE, C. Disorganized Capitalism. Londres: Polity Press, 1985.

ROBERTS, P.; SYKES, H. Urban regeneration: a handbook. London: SAGE Publications, 2000.

RODWIN, L.; HOLLISTER, R. M. Cities of the Mind: images and themes of the city in the Social Sciences. New York: Plenum Press, 1984.

SANCHEZ, F. A reinvenção das cidades na virada de século: agentes, estratégias e escalas de ação política. Revista Sociologia e Política, Curitiba, 16, p. 31-49, jun. 2001.

SASSEN, S. The global city. Princeton: Princeton University Press, 1991.

SIMMEL, G. As grandes cidades e a vida do espírito (1903). MANA, v. 11, n. 2, p. 577-591, out. 2005. Disponível em: <http://www.scielo.br/pdf/mana/ v11n2/27459.pdf>. Acesso em: 05 jan. 2016.

SINGER, P. O uso do solo urbano na economia capitalista. In: MARICATO, E. (Org.). A produção capitalista da casa (e da cidade) no Brasil industrial. São Paulo: Alfa-Omega, 1982. p. 21-36.

SOUZA, M. L. de. O desafio metropolitano: um estudo sobre a problemática sócio-espacial nas metrópoles brasileira. Rio de Janeiro: Bertrand Brasil, 2000.

TOPALOV, C. Da questão social aos problemas urbanos: os reformadores e a população das metrópoles em princípios do Século XX. In: RIBEIRO, L. C. Q.; PECHMAN, R. (Org.). Cidade, povo e nação: gênese do urbanismo moderno. Rio de Janeiro: Civilização Brasileira, 1996, p. 23-51.

URBAN WORLD FORUM, 2002. Reports On Dialogues Ii - Sustainable Urbanization. Disponível em: < http://www.unchs.org/uf/aii.html>. Acesso em: 13 jun. 2002.

VAINER, C. Pátria, empresa e mercadoria: notas sobre a estratégia discursiva do Planejamento Estratégico Urbano. In: ARANTES, O.; VAINER, C.; MARICATO, E. A cidade do pensamento único: desmanchando consensos. Petrópolis: Editora Vozes, 2002. p. 75-104.

WACQUANT, L. Os condenados da cidade: estudos sobre marginalidade avançada. Rio de Janeiro: Revan, 2005.

WIRTH, L. O urbanismo como modo de vida. In: VELHO, O. G. (Org.). O fenômeno urbano. 4. ed. Rio de Janeiro: Guanabara, 1987.

ZUKIN, S. Paisagens urbanas pós-modernas: mapeando cultura e poder. In: Arantes, A. A. (Org.). O espaço da diferença. Campinas: Papirus, 2000, p. 80-103. 
Rosemere Santos Maia - Possui Graduação em Serviço Social pela Universidade Federal do Rio de Janeiro, Especialização em Teoria e Metodologia do Serviço Social pela Universidade Federal Fluminense. Mestrado em Serviço Social pela Universidade Federal do Rio de Janeiro e Doutorado em Geografia pela mesma Universidade. Possui Pós-Doutorado em Sociologia pela Universidade Nova de Lisboa. Atualmente, é Professora Associada da Universidade Federal do Rio de Janeiro.

Carlos José Cândido Guerreiro Fortuna - Possui graduação em Sociologia pela Escola Superior de Estudos Sociais e Econômicos. Doutorado em PhD Sociology pela State University of New York - Binghamton. Atualmente é Professor da Universidade de Coimbra.

Contribuição de cada autor no desenvolvimento do artigo:

A versão inicial do artigo foi apresentada pela primeira autora durante um evento interno promovido pelo grupo de estudos coordenado pelo segundo autor (seu supervisor no estágio pós-doutoral). As reflexões/questões daí emanadas motivaram os autores à escrita de um trabalho em coautoria. Deu-se, a partir de então, discussão/colaboração entre ambos durante todo o processo, desde a (re)definição dos marcos teóricos/conceituais, passando pela redação e revisão crítica do trabalho.

Recebido para publicação em 28 de julho de 2016 Aceito para publicação em 02 de setembro de 2016 